\title{
Understanding the Social Distance of Diponegoro University Students toward Disability Group
}

\author{
Lintang Ratri Rahmiaji ${ }^{1}$, Hapsari Dwiningtyas Sulistyani ${ }^{2}$, Turnomo Rahardjo ${ }^{3}$ \\ \{lintangratri84@gmail.com ${ }^{1}$, hapsarisulistyani@yahoo.com ${ }^{2}$, turnomorahardjo@gmail.com ${ }^{3}$ \} \\ Universitas Diponegoro, Indonesia ${ }^{1,2,3}$
}

\begin{abstract}
This research is a quantitative survey study conducted to measure social distance (tolerance level) of students towards minority groups, especially disability groups. The strategy of eliciting attitudes and behaviors of tolerance must of course be based on an understanding of the social distance that exists between students and minority groups. The population of this research is all Undip students who are still active in 2019. The conclusion that can be conveyed in this study is that most students from the 12 faculties don't have social distance towards disability groups. Social distance strengthens when contextual mental limitations are focused, especially on activities and studying at Undip. Overall, in terms of the faculties at Undip, the least distant to groups with disabilities both physically and mentally is the Faculty of Engineering, while the one with the highest social distance is the Vocational School. The reason is Undip's lack of readiness in providing appropriate learning facilities for disability groups, besides that students feel afraid of being mistaken in facing disability groups. This research shows the potential for conflict and resistance from Undip students towards the minority groups around them.
\end{abstract}

Keywords: Social Distance, Minority Groups, Disabled Groups, Social Science Paradigm.

\section{Introduction}

Understanding, attitude, and sympathetic behavior on people from different groups are essential factors in multicultural society like Indonesia, as a consequence of realizing social harmony needed to be accounted for in accordance with what is offered to minority groups. Referring to the National Commission on Human Rights (2016), the scope of minority groups within Indonesia is very diverse which includes minority groups: ethnicity, race, religion/belief, disability, and sexual orientation/gender identity. The respect for minority groups has been regulated by the state, for example for people with disability. Law Number 8 of 2016 regarding People with Disability explicitly stipulates as stated in Article 3, paragraph (a) that the state is obliged to realize respect, promotion, protection, and fulfillment of human rights and paragraph (d) which stipulates that the state protects people with disability from neglect and exploitation, harassment, and all discriminatory acts and violates human rights. The embodiment of state freedom is implemented in all lines of life; one of them is education. Educational institution is one of the state's instruments which is also obliged to realize protection and disability.

University as the highest educational institution has a very important role in shaping the perspective of students so that they can be more empathy and tolerant toward minority groups. 
Moreover, students from a university are the meeting point of various diversity in Indonesia; one of them is a group of students with special needs, or disability. The Minister of Research, Technology, and Higher Education of the Republic of Indonesia Regulation Number 46 of 2017 regarding Special Education and Special Service Education in Higher Education, explains that the purpose of conducting special education is to respect diversity and equality for students with special needs as stipulated in article 3 paragraph (3). This is reiterated in the statement that the obligation of higher education leaders is to facilitate the formation of an inclusive culture on campus and an increase in the competence of lecturers and education personnel in providing services to students with special needs. The specific definition is more directed at students who have: first the potential for special intelligence and talent and second students who have difficulty in following the learning process due to physical, emotional, mental, social limitations; includes students who have difficulty including: a) blind; b) deaf; c) orthopedically handicapped; d) mentally disabled; e) communication breakdown; f) slow learning; g) specific learning difficulties; h) autism spectrum disorders; and i) attention disorder and hyperactivity [1][2].

The strategy of eliciting attitudes and behaviors of tolerance must, of course, be based on an understanding of the social distance that exists between students and minority groups. This study will examine the social distance (level of tolerance) of Diponegoro University students on minority groups, especially those with disability. The selection of Diponegoro University as the research locus is based on its position as one of the largest and of the best state universities in Indonesia. As one of the largest state universities, it attracts many students from various different backgrounds. Diponegoro University's readiness to provide educational services for all students becomes important.

Supriono's research (2014) concerning the accessibility of the physical environment and Diponegoro University's academic services to the disabled people shows that the physical environment in the facilities and infrastructure are considered not meeting the needs of the disabled group. This is because in 2014, Diponegoro University occupied a new location and the number of students with disabilities is still low, but on the other hand, it cooperates with the Indonesian Blind Association (PERTUNI), so that it shows Diponegoro University's concern with the rights of people with disabilities especially for the blind. In the same year, Soleh's research [3] also showed the unpreparedness of state universities in Yogyakarta to carry out the mandate of the law namely the Indonesian Art Institute (ISI), Gajah Mada University (UGM), Yogyakarta State University (UNY), and State Islamic University (UIN) Sunan Kalijaga. The results showed that education at UGM, UNY, and ISI had an integrated system, while at UIN had an inclusion system, which was felt to be more accommodating, and able to provide services to disabled students.

Talking in the disabled domain requires the importance of discussion about inclusiveness. Inclusive becomes the main criteria, especially since the ratification of the Convention on the Rights of People with Disabilities (CRPD) in 2011. Disability Rights Activities as well as Director of Disabled Services Center of UIN Sunan Kalijaga Yogyakarta, Arif Maftuhin, mentioned that in general there are four indicators of inclusivity, namely: participation, availability, accessibility, and inclusion culture. This is in line with the inclusiveness indicators set by UNESCO, among others, the accessibility of buildings and infrastructure, positive social environment, affordability of facilities, availability, quality of service, and participation of disability. Participation means the disabled people can actively participate in all aspects of life as citizens. Then, availability means that the disabled have the right to services, facilities, and infrastructure to fulfill the disability rights in accordance with the mandate of laws and government regulations. Meanwhile, accessibility is the ease for the 
disabled to get benefits from services, facilities, and infrastructure without any obstacles. What is meant by inclusion culture is the attitude of the government and the community which is not discriminatory, and respects the right of people with disabilities.

Among the four indicators of inclusiveness, inclusive culture is a fundamental element. This is because if inclusive has become entrenched, participation, availability, accessibility will be realized automatically. Otherwise, if it is not initiated from an inclusive culture, the fulfillment of participation, availability, and accessibility will become a burden. Furthermore, inclusion is a way of thinking and acting that allows each individual to feel accepted and valued. In the context of the educational environment, the principle of inclusion encourages every element involved in the learning process, striving for a learning environment where all students can learn effectively and together.

In the context of cultural communication, inclusiveness is built through intercultural interaction. Various social constraints such as stereotypes, prejudices, and discrimination are closely related to the social distance that is the focus of this research. Distance here is not understood as distance or biological/genetic distance. The concept of social distance is proposed by Emory S. Bogardus. According to Bogardus in Karakayali [4], feelings of sympathy and affection are key elements of social distance: when there is little understanding and sympathy, there arises social distance. Whereas if understanding and sympathy are high, then social distance will be close Borgadus in Karakayali [4]. This study uses a list of questions adapted from the Borgadus scale which are contextualized within the scope of students and universities. This research will measure the social distance between the informants (students) and the disability groups on campus with the main questions of this study are:

a) What is the social distance between students and disability groups?

b) What is the degree of limitation of association with disability groups at the level of knowledge, attitude, and behavior?

\section{Research Method}

This research is a quantitative survey study conducted to measure the social distance of students on disability groups. The population of this research is all Diponegoro University student bodies which are still active in 2019. The total number of Diponegoro University students is: 42271 students. The sample size calculation shows that with a population of 42271 , with a confidence level of $95 \%$ and a confidence interval of 5 , the number of samples in this study is 415 . The proportion of the sample in this study will be made on the basis of the proportion of male and female students and the proportion of the number of students in each faculty. Data collection techniques use self-administrated questionaire and literature review about social distance on minority groups. The data obtained are analyzed with associative statistics with the Chi Square test.

\section{Results and Discussion}

This research is conducted on 415 Diponegoro University students as respondents. Respondents are randomly taken from 12 faculties at Diponegoro University (Faculty of Medicine, Engineering, Science and Mathematics, Animal Husbandry and Agriculture, 
Fisheries and Marine Science, Public Health, Psychology, Law, Economics and Business, Cultural Studies, and Social and Political Sciences) and Vocational School. In each faculty, the number of respondents is $34-37$ students.

\section{Social Distance to Physical Disabilities}

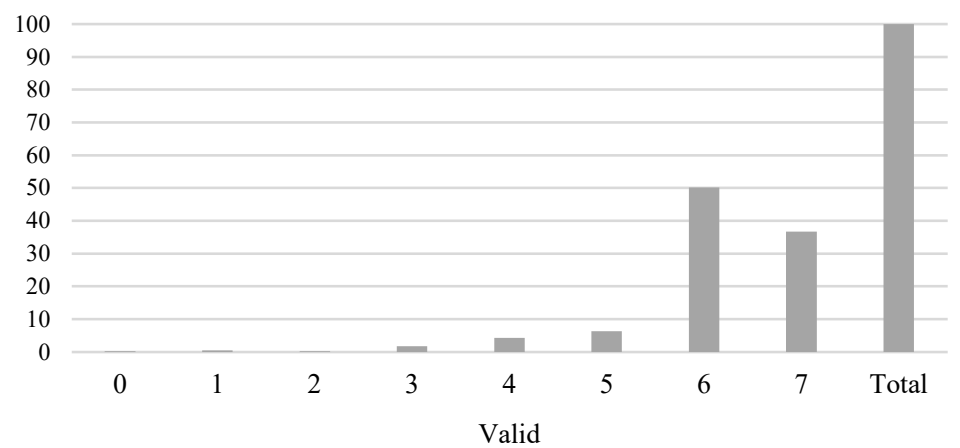

Referring to the Bogardus scale, where scale 0 means there is no interaction, scale 1-2 means social distance is high, scale 3-4 means social distance is medium, scale 5-6 means social distance is low, and scale 7 means there is no distance. Based on the results of the study, in general, as many as 6\% of Diponegoro University students have moderate social distance on physical disability groups, and $56.4 \%$ of Diponegoro University students are socially low, while as many as $36.6 \%$ do not mind being associated with minority groups. However, there is one person who totally rejects the thought of associating with a minority group, and 3 respondents have a high rejection of a minority group. This finding shows the potential social distance from Diponegoro University students on physical disability groups. On the other hand, acceptance of the mental disability group also experiences significant obstacles. Only $17.1 \%$ which is not socially distant from the mental disability group; there is $52.1 \%$ of Diponegoro University students who are socially low, and $14.5 \%$ of students recorded having social distance; while $9.4 \%$ of students build high social distance, and $7 \%$ or 29 people refuse to connect with the mental disability group. Diponegoro University students' social distance from the mental disability group is higher than the physical disability group.

Social Distance To Mental Disabilities Group

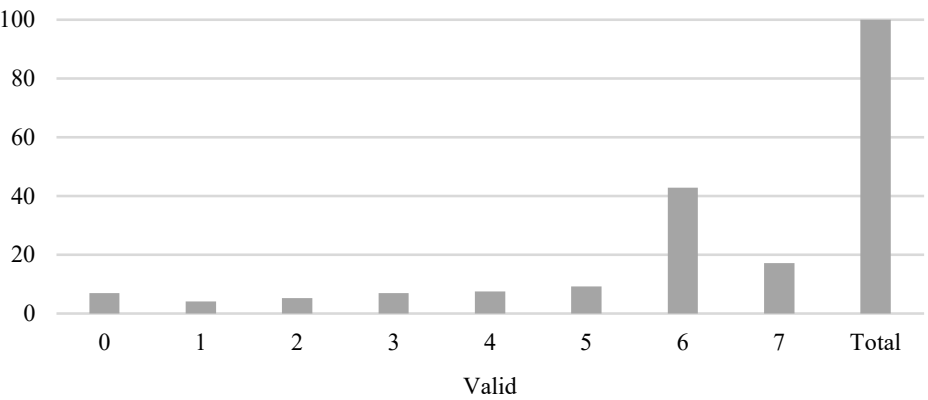

In a more specific context, based on faculty categorization in Diponegoro University, it can be mapped how the social distance of Diponegoro University students on disability groups, in terms of activities at Diponegoro University environment and study at Diponegoro University. In the context of activities at Diponegoro University environment in general, most 
students do not question the presence of individuals who have physical limitations to take advantage of existing facilities and activities at Diponegoro University campus. Students from 6 faculties namely Faculty of Engineering, Faculty of Agriculture and Animal Husbandry, Faculty of Public Health, Faculty of Social and Political Sciences, Faculty of Law, and Faculty of Economics and Business fully accept the presence of physical disability groups for activities at Diponegoro University. Rejection, even though the value is low, appears in the Vocational School, Faculty of Psychology, and Faculty of Fisheries and Marine Science, Faculty of Cultural Studies, namely as much as $8 \%$ of the total number of students.

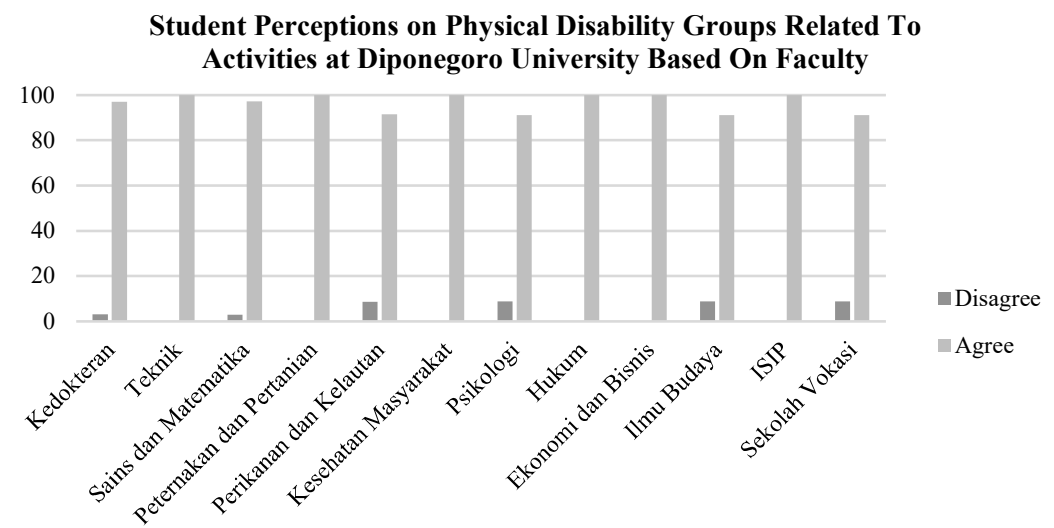

When compared to the acceptance of the presence of mental disability groups at Diponegoro University environment for activities, the number of rejections toward physical disabilities is indeed lower. At the Faculty of Law, there is absolutely no rejection. However, an interesting fact is actually shown by Vocational School, where the number of respondents who reject the mental disability group is higher than those who accept, which is $58.8 \%$. In addition, the other who also significantly rejects the activities initiated and attended by individuals who have mental disabilities are the Faculty of Cultural Studies, Faculty of Economics and Business, and Faculty of Fisheries and Marine Science.

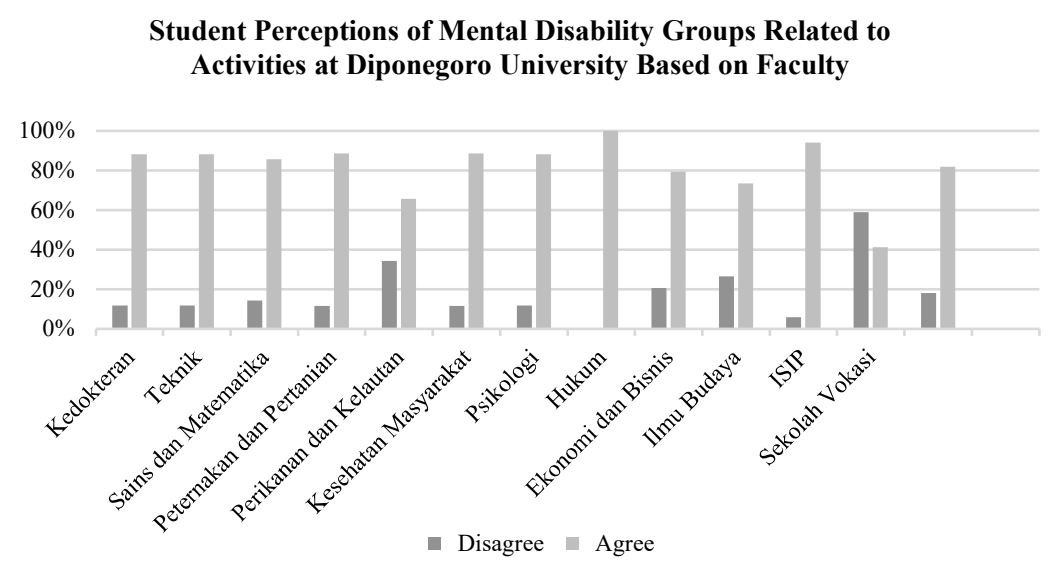

Meanwhile, in terms of whether the physical disability group can be accepted to be a student at Diponegoro University environment based on the faculty shows that only at Faculty 
of Politics and Social Sciences which is significant at $14.7 \%$ of students who reject the idea of student acceptance for that context. Other faculties that also reject are Faculty of Mathematics and Sciences, Faculty of Fisheries and Marine Science, Faculty of Public Health, Faculty of Law, Faculty of Cultural Studies and Vocational School.

\section{Student perceptions of Physical Disability Groups Related to Studying at Diponegoro University Based on Faculty}

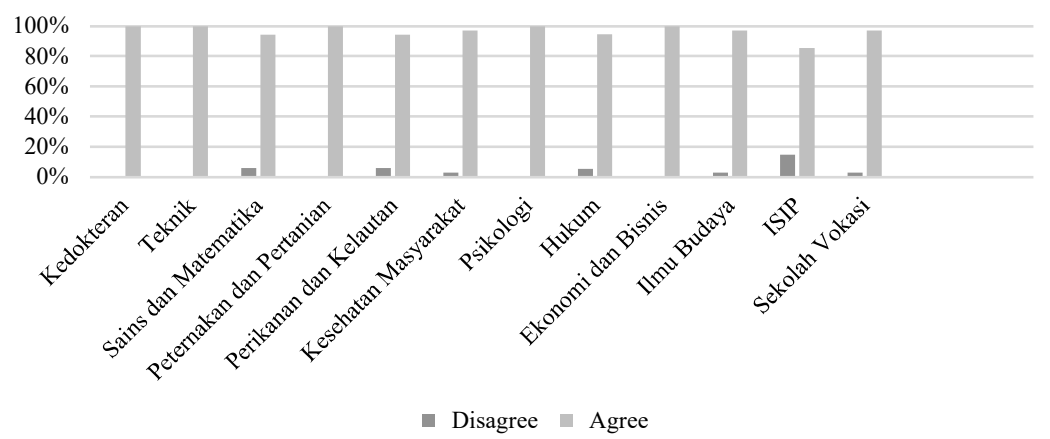

Student Perceptions of Mental Disabilty Groups Related to Studying at Diponegoro University Based on Faculty

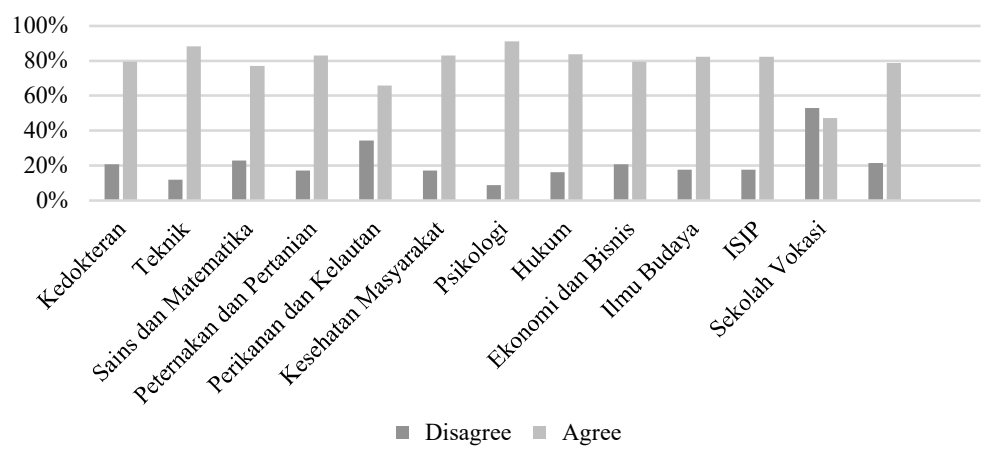

The data also show that rejection begins to be high when asked about whether Diponegoro University is allowed to accept a mental disability group to study at Diponegoro University, almost all faculties reveal high rejection data. Vocational School remains the highest at 52.9\%; the others are Faculty of Fisheries and Marine Science, Faculty of Mathematics and Science, Faculty of Medicine, Faculty of Economics and Culture. What is also interesting is the Faculty of Cultural Studies also has students who are socially distanced from mental disability groups. In this case, it can also be seen that the faculty that has the lowest social distance to the two types of disability groups is the Faculty of Psychology, while the Faculty which has the highest social distance is the Vocational School. Overall, in terms of faculties at Diponegoro University, the least distant groups with disabilities both physical and mental are: 1. Faculty of Engineering, 2. Faculty of Animal Husbandry and Agriculture, 3. Faculty of Psychology. While those with the highest potential social distance are 1. Vocational School, 2. Faculty of Animal Husbandry and Agriculture, 3. Faculty of Cultural Studies. 
Identity is an abstract concept and has many facets that have a significant role in intercultural interaction [5]. Identity is the main thing for most people, because identity talks about who we are, who other people are, how we understand who we are, and how we communicate our identity to others. It functions as a bridge between culture and communication. It is important, because we communicate our identity to others and we learn to know who we are through communication [6][7]. In order to lead a non-discriminatory life today, the important thing to do is how we can communicate effectively with people who are culturally different. In a sense, how anyone can reduce the occurrence of cultural misunderstanding, not the creation of closeness or relational satisfaction [8]. Cultural misunderstanding has the potential to create tension and conflict. On the other hand, recognition of cultural differences will enable everyone to establish more meaningful relations. Thus, the challenge faced is how everyone is willing to "learn" to accept cultural differences. This is what makes the urgency of developing inclusive education in tertiary institutions.

Inclusive education can simply be interpreted as the concept of education for all who do not tolerate discrimination on students. Inclusive education believes that all children can basically learn. It seeks to enable the structure, system and methodology of education to meet the needs of all children and respect the diversity of learners, ranging from differences in gender, race, language, disability, as well as children with HIV-AIDS status and potential diseases obstructing the rights of students. The pattern of inclusive education has various meanings. Stain back argues that inclusive school is a classroom that holds all students in the same class. The tertiary institution should provide an education program where every child can be accepted, be part of the class. Staub and Peck suggest that inclusive education is the placement of children which shows that regular class is a place of learning that is relevant for children with disabilities, regardless of the type of disability and whatever gradation is.

Therefore, inclusion is an educational and social philosophy. In inclusion, everyone is a valuable part of being together, whatever their differences. In education, this means that all children, regardless of their abilities or disabilities, socio-economic background, ethnicity, culture or language, religion or gender, are united in the same community school [9]. Inclusive education with regard to activities provides an appropriate response to the existence of differences from good learning needs. It is an approach that pays attention to how to transform the education system so that it is able to respond to student diversity and enable teachers and students to feel comfortable with diversity and see it more as a challenge and enrichment in the learning environment than as a problem.

Furthermore, inclusion is a way of thinking and acting that allows each individual to feel accepted and valued. The principle of inclusion encourages every element involved in the learning process and attempts a learning environment where all students can learn effectively and collectively. Thus, no students will be rejected or expelled from school for reasons of not being able to meet the established academic standards. Although, on the other hand, some parents are worried that their children who have disabilities will be teased or tempted by the surrounding environment.

The findings of this study indicate that there is a significant potential social distance between Diponegoro University students and disability groups, especially in mental disabilities, while physical disability is still at a tolerant level. This shows that Diponegoro University has begun to pay attention on the right to have access to education for disability groups although it still needs a lot of improvement. Likewise, the matter of fostering a culture of inclusiveness on campus. The rejection of disability groups shows that Diponegoro 
University students still do not have an inclusive culture and tend to discriminate minorities, in this case, the disability group.

\section{Conclusion}

This study aims to measure the social distance of Diponegoro University students toward minority groups. The conclusion that can be conveyed in this study is that most students from the 12 faculties do not question the presence of individuals who have physical limitations to take advantage of existing facilities and activities at Diponegoro University campus. Social distance strengthens when contextual mental limitations are focused, especially on activities and studying at Diponegoro University. Overall, in terms of faculties at Diponegoro University, the least distant groups with disabilities both physical and mental are, 1. Faculty of Engineering, 2. Faculty of Animal Husbandry and Agriculture, 3. Faculty of Psychology. While those with the highest potential social distance are 1. Vocational School, 2. Fac. Animal Husbandry and Agriculture, 3. Faculty of Cultural Studies. The reason is Undip's lack of readiness in providing appropriate learning facilities for disability groups, besides that students also feel awkward and afraid of being wrong in dealing with disability groups, most recently the results of this research indicate the potential for cultural conflict and also the resistance of Undip students to existing minority groups around them. There is an urgency to immediately socialize the inclusive culture to increase empathy and minimize potential for discrimination toward minority groups at Diponegoro University environment.

\section{References}

[1] L. A. Baxter and E. R. Babbie, The basics of communication research. Cengage Learning, 2003.

[2] S. W. Littlejohn and K. A. Foss, Encyclopedia of communication theory, vol. 1. Sage, 2009.

[3] A. Soleh, "Kebijakan perguruan tinggi negeri yogyakarta terhadap penyandang disabilitas," $J$. Pendidik. Islam, vol. 3, no. 1, pp. 1-30, 2014.

[4] N. Karakayali, "Social distance and affective orientations 1," in Sociological Forum, 2009, vol. 24, no. 3, pp. 538-562.

[5] L. A. Samovar, R. E. Porter, E. R. McDaniel, and C. S. Roy, Communication between cultures. Nelson Education, 2017.

[6] J. Martin and T. Nakayama, Experiencing intercultural communication: An introduction. McGraw-Hill Higher Education, 2013.

[7] F. E. Jandt, An introduction to intercultural communication: Identities in a global community. Sage Publications, 2017.

[8] E. Griffin, "A First Look at Communication Theory McGraw-Hill,” New York, NY, 2012.

[9] G. E. Markali, "Hubungan antara identifikasi etnis dengan jarak sosial terhadap etnis Jawa pada etnis Tionghoa (Studi kasus pada mahasiswa etnis Tionghoa Universitas Katolik Widya Mandala Surabaya).” Widya Mandala Catholic University Surabaya, 2007. 